\title{
Metamaterial Concentrator for Thermal Energy Harvester
}

\author{
Rapha Nichita Kaikatui ${ }^{1 *}$, Adik Putra Andika ${ }^{1}$, Vinsenius Letsoin ${ }^{1}$, Paulus Mangera ${ }^{1}$, \\ Damis Hardiantono ${ }^{1}$, Yogo Adhi Nugroho ${ }^{2,3}$, Herry Susanto ${ }^{4,5}$, and Haryo Wibowo ${ }^{6}$ \\ ${ }^{1}$ Department of Electrical Engineering, Musamus University, Kamizaun Street, \\ Merauke 99611, Papua, Indonesia \\ ${ }^{2}$ Individual Researcher, Alumni Graduate School of IPB University, Bogor, Indonesia \\ ${ }^{3}$ Data Processing, Rumah Paper - Editage Services, Jl. Tokala No.1, Malang 65146, Indonesia \\ ${ }^{4}$ Department of Mechanical Engineering, Darma Persada University, Jl. Taman Malaka Selatan \\ No.22, Jakarta 13450, Indonesia \\ ${ }^{5}$ Graduate School of Renewable Energy, Darma Persada University, Jakarta, Indonesia \\ ${ }^{6}$ Institute of Energy and Power Engineering, Zhejiang University of Technology, No. 38 Zheda Road \\ Hangzhou 310027, P.R. China.
}

\begin{abstract}
Energy demand increases in line with rapid technological advances. Research on the harvesting of renewable energy continues to be done to make efforts to convert heat energy, which is very abundant in our daily environment. Thermoelectric technology is an alternative source in answering energy needs and can produce energy on a large and small scale. Thermoelectric technology works by converting heat energy into electricity directly, or from electricity to cold. This research presents an experimental study conducted to find out the thermoelectric characteristics of the TEC in the reversal function, with heating and cooling tests on each side of the TEC type thermoelectric element, carried out to obtain the voltage value as the electrical potential generated from this element. The result is thermoelectric potential to generate DC electricity but is very limited in the function of maintaining a heat source on the hot side element. This research then proposes thermal metamaterial that functions as a collector of thermal energy in the method of converting thermal energy into DC electrical energy for the application of low power consumption communication systems.
\end{abstract}

Key words: Heat energy, metamaterial thermal concentrator, thermal harvesting

\footnotetext{
*Corresponding author: kaikatui_ft@unmus.ac.id
} 


\section{Introduction}

Statistical results show that more than $60 \%$ of energy wasted worldwide is mostly waste heat [1]. The amount of wasted heat energy that comes from environmental heat, electronic devices, automotive exhausts, and industrial processes all produce wasted heat energy that can be converted to electricity using thermoelectrics. The thermoelectric effect refers to the ability to produce electric current from temperature differences between one material side and another. Conversely, applying a thermoelectric power voltage can cause one side of the material to heat while the other side remains cold or one side cools while the other remains hot. The heat sink is used to help increase heat release on the cold side, thereby increasing the efficiency of the module. The potential for power generation from a single thermoelectric module will vary depending on the size, construction, and temperature difference. The greater temperature difference between the hot side and the cold side of the module will result in greater voltage and current. Thermoelectric modules can also be connected either in series or parallel like a battery to produce a voltage or electric current.

The use of thermoelectrics is limited to the low efficiency that occurs because materials that have good electrical conductor properties tend to be good heat conductors. It means that at the same time, the temperature difference produces a voltage, the temperature difference also decreases, thus weakening the current. Materials that have high electrical conductivity and high thermal conductivity misbehave in changing temperature differences into voltage sources. Therefore, an effort is made to increase the efficiency of the thermoelectric module.

A concentrator can theoretically be more efficient at harvesting heat energy each time the heat flux from changing direction can be concentrated to specific nuclei or locations. Harvesting of heat energy through manipulation of hot and focused fluxes has been proposed by researchers as a practical extension of work on thermal metamaterials and has practical applications for autonomously driven sensors or self-activated devices [2].

A great interest in metamaterial research has been observed. Metamaterial material is a new material made to obtain special properties that would not get naturally in the universe. This material is made by combining several composite material elements such as metal and plastic. The metamaterial does not have properties derived from its parent material but is completely new according to its structural design. One special characteristic of the metamaterial is the accuracy of the shape, geometry, size, orientation, and arrangement will produce properties that are capable of manipulating electromagnetic waves by blocking, absorbing, expanding, or also deflecting waves. It is this particular characteristic that thermal metamaterial researchers use to regulate thermal emissions emitted from heat sources. Metamaterials are artificially created materials that show properties that are not detected in natural materials. In research [3], thermal metamaterials can be used to control heat flux and control temperature differences. Metamaterials are engineered for their electromagnetic focus responses on $\varepsilon$ and $\mu$ as the main material of attractive properties. Metamaterials are engineered for their thermal properties focusing on different material properties, including, but not limited to, thermal conductivity and electrical conductivity ( $\kappa$ and $\sigma$ ) [4]. Figure 1 shows some material examples that cover various $\kappa$ and $\sigma$ characteristics. 


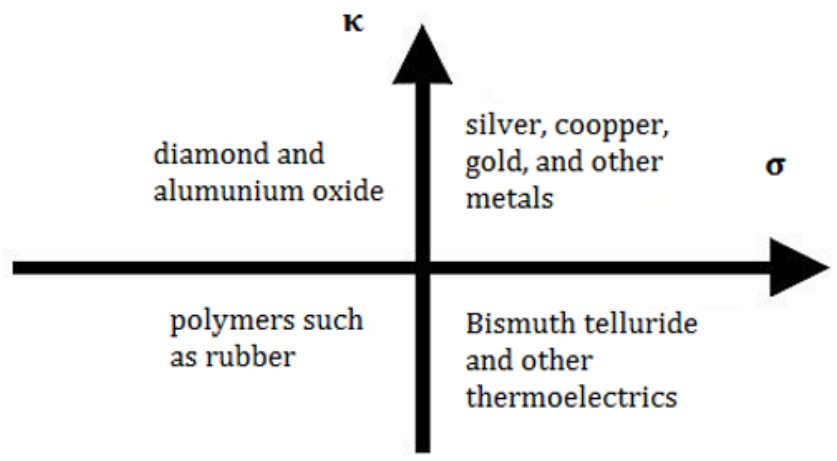

Fig. 1. Electrical verses thermal conductivity [4].

Note that $\kappa$ and $\sigma$ are not zero or negative in any quadrant, as is the case when evaluating $\varepsilon$ and $\mu$. Existing chemical compounds and natural materials provide for many combinations of $\kappa$ and $\sigma$. However, the allure of a thermally-tuned metamaterial is not only that the designer may be able to independently select the value of $\kappa$ and $\sigma$ needed for the material application. It is that the material's $\kappa$ and $\sigma$ may be controlled within a certain range via a mechanical actuation scheme.

Some authors have examined the efficiency of triangular fins and compared them with fin-shaped rectangles [5]. It can be concluded that triangular-shaped triangular designs have lower Biot numbers on heat transfer compared to rectangular fin designs due to triangular fins has a smaller surface area. Otherwise, in this study, the concept of material used in this study is to use a combination of three materials with different thermal conductivity to direct the heat flux to a certain location, this concept then becomes a thermal metamaterial. The concept of metamaterial in thermal directing applications has been explained and applied by several authors [5-8]. Also, based on research [9] later in this study, then experimented to determine the potential of a thermoelectric, which can then be combined with a concentrator metamaterial.

\section{Design of Metamaterial}

With the basic design carried out by [10] the idea to improve and optimize the design of thermal concentrators in the form of floral metamaterials using triangular designs (threedimensional perspectives) on the petals in the form of thermal concentrator metamaterials because the lower levels are triangular in the form of dissipated hot fins to the environment as shown in Figure 2. 


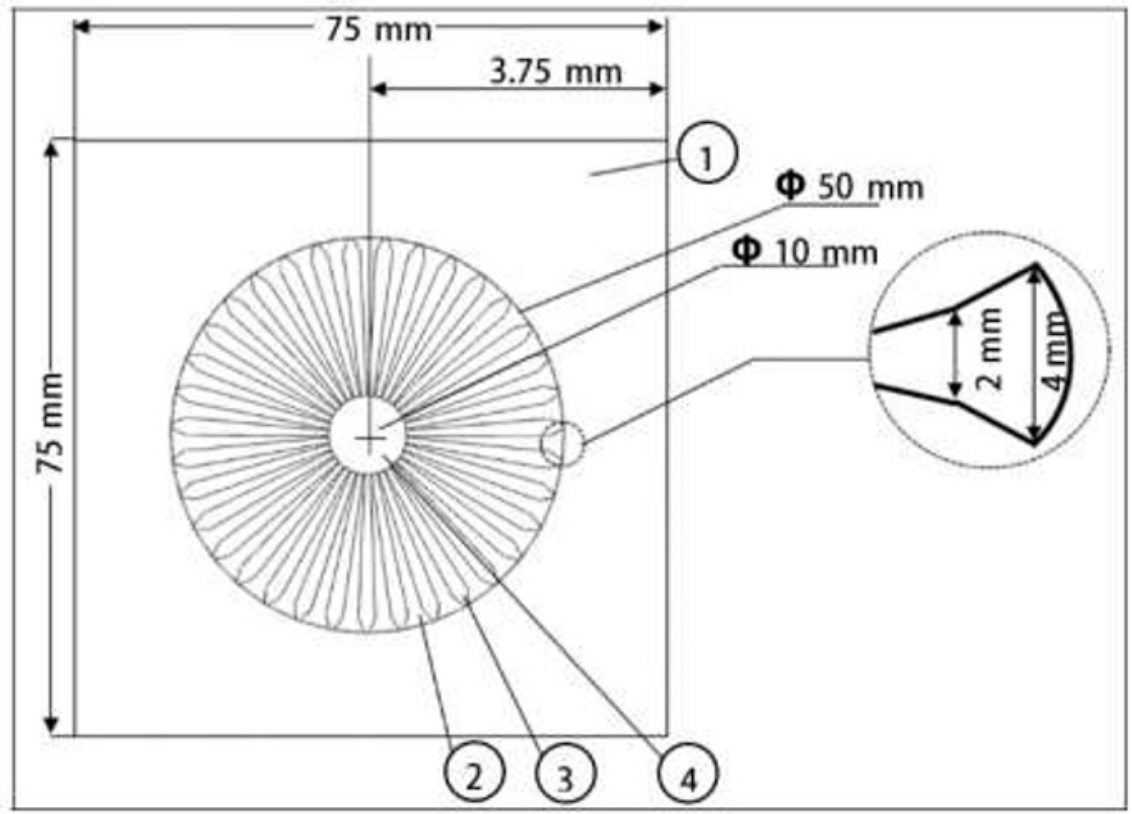

Fig. 2. Design of Thermal Concentrator [9].

Numerical transient thermal analysis has been carried out by Muslimin et al. [9] to analyze the design of flower-shaped metamaterials that have been optimized with profiles, as seen in Figure 3.

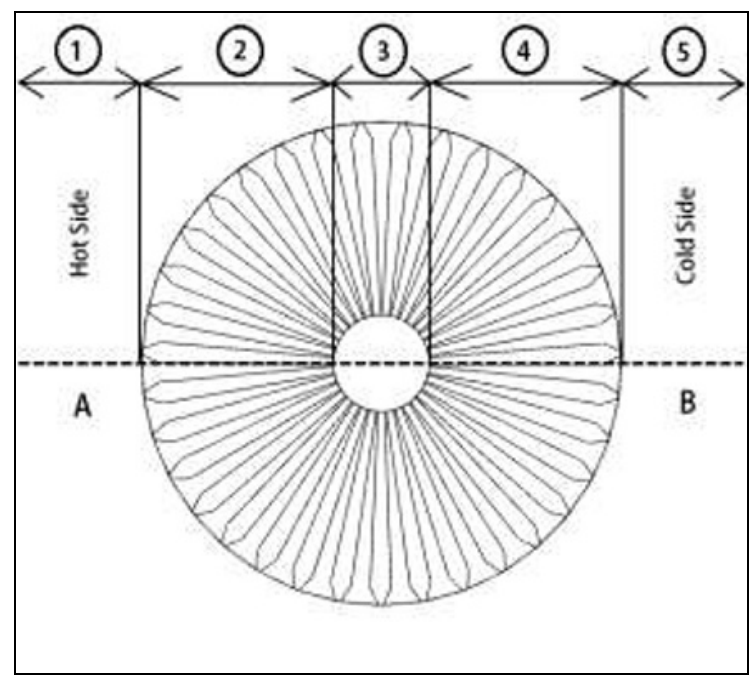

Fig. 3. Zone temperature profile of metamaterial thermal concentrator. [9] 


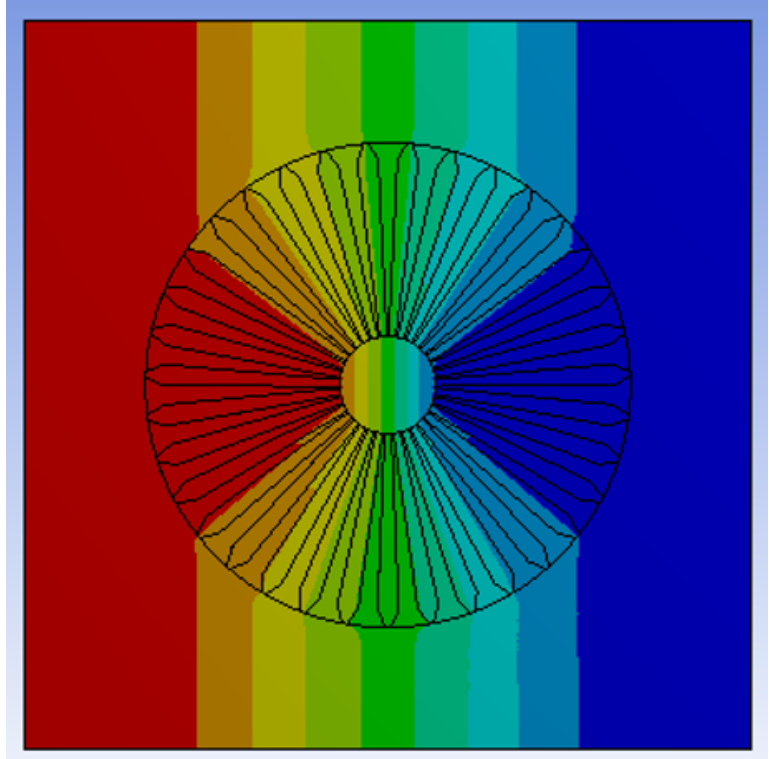

Fig. 4. Temperature distribution [9].

Muslimin et al. [9] divide the temperature profile zone into five parts, namely number 1 is the background zone, from the hot side edge to the outer circle of the concentrator, number 2 is the petal part from the outer circle of the concentrator to the circle boundary in the concentrator, number 3 along the core diameter, number 4 is from the right side of the inner core boundary to the right side of the outer circle boundary, and number 5 is from the outer circle to the edge of the cold side material as seen in Figure 3. The results of this design show that a thermal concentrator can direct heat to the center of the material and harvest heat flux from an area wider than the heat source and then concentrate it well on the core part of the concentrator, as shown in Figure 4.

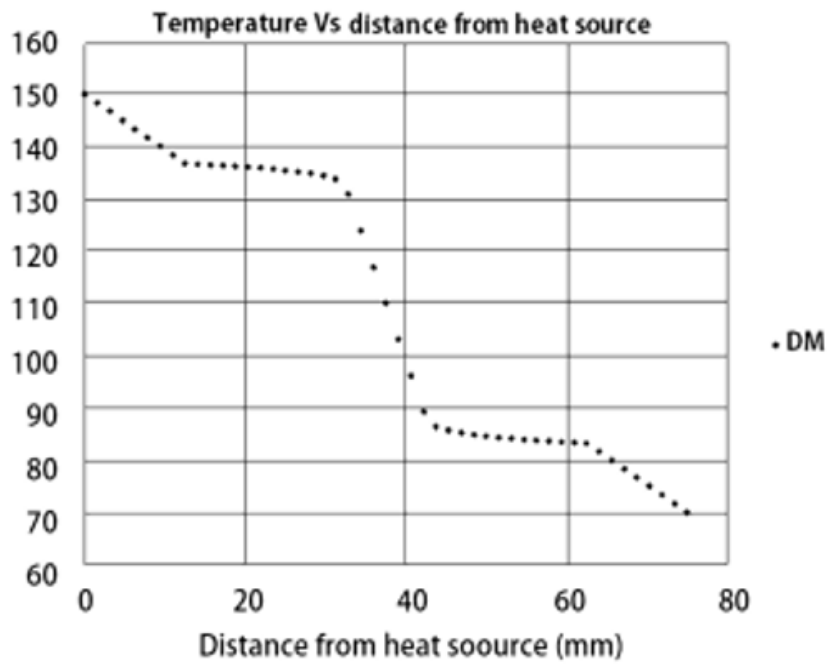

Fig. 5. Temperature profile along [9]. 
Figure 5 is the result of a numerical simulation of the temperature distribution of thermal concentrations in the metamaterial [9]. Next, a thermoelectric analysis will be displayed to see its potential as a source of electrical energy. Then the simulation results can then be taken into consideration in utilizing concentrators as thermal energy harvesters to be configured with conventional thermoelectric devices.

\section{Testing Scheme}

The stages of conventional thermoelectric testing are detailed as follows:

i. Conventional thermoelectric data is used as comparative data on the potential of electrical energy that can be produced by thermoelectrics

ii. The thermoelectric testing is TEC1-12706 and TEC1-12715. The specifications of the TEC device can be seen in Table I.

Table 1. Specifications of the TEC.

\begin{tabular}{|c|c|c|c|c|c|}
\hline \multicolumn{3}{|c|}{ TEC1-12706 } & \multicolumn{3}{c|}{ TEC1-12715 } \\
\hline $\begin{array}{c}\text { Hot Side } \\
\text { Temperature }\end{array}$ & $25{ }^{\circ} \mathrm{C}$ & $50{ }^{\circ} \mathrm{C}$ & $\begin{array}{c}\text { Hot Side } \\
\text { Temperature }\end{array}$ & $27{ }^{\circ} \mathrm{C}$ & $50^{\circ} \mathrm{C}$ \\
\hline DTmax $\left({ }^{\circ} \mathrm{C}\right)$ & 66 & 75 & DTmax $\left({ }^{\circ} \mathrm{C}\right)$ & 70 & 79 \\
\hline $\operatorname{Imax}(\mathrm{A})$ & 6.4 & 6.4 & $\operatorname{Imax}(\mathrm{A})$ & 15.0 & 15.0 \\
\hline $\operatorname{Vmax}(\mathrm{V})$ & 14.4 & 16.4 & $\operatorname{Vmax}(\mathrm{V})$ & 16.0 & 17.2 \\
\hline Qmax (W) & 50 & 57 & Qmax (W) & 150.2 & 164.2 \\
\hline
\end{tabular}

iii. Data retrieval is carried out in the laboratory using equipment, as shown in Figure 6. Data retrieval of TEC1-12706 and TEC1-12715 under TEC conditions does not get a flow injection.

iv. In the thermoelectric placed between the heat sink, directed the blower with a temperature of $330{ }^{\circ} \mathrm{C}$ on the hot side and 5VDC cooling fan on the cold side in the hope that each side can maintain its temperature so that the goal to obtain $\Delta \mathrm{T}$ can be achieved and then generate a voltage source.

v. The test is carried out based on the length of time until it reaches a maximum temperature (Tmax), which can be absorbed by the thermoelectric.

vi. Output data is controlled using Arduino Uno.

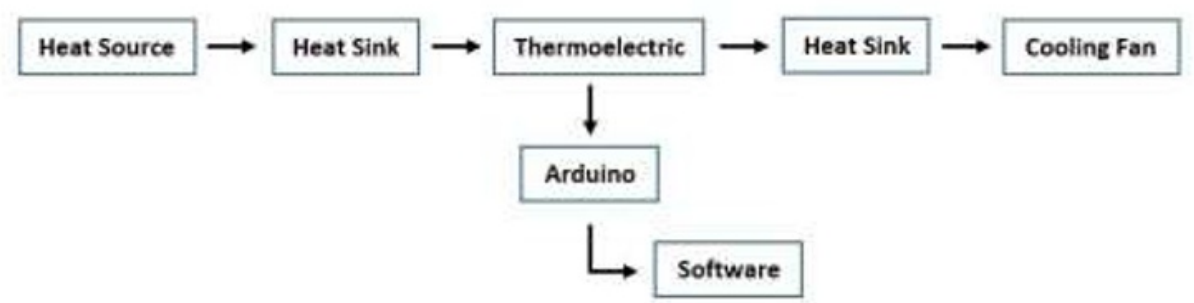

Fig. 6. Thermoelectric testing scheme 


\section{Result}

This thermoelectric test produces data in the form of output voltage, hot side temperature, cold side temperature, and $\Delta \mathrm{T}$ as a function of time. Laboratory-based testing. Two experiments were carried out. The temperature variations given to the thermoelectric are carried out up to the maximum temperature that can be absorbed by the two thermoelectric types. The temperature difference generated from this experiment is not as high as previously thought. This is because the fan that is used as a cooler is not optimal in removing heat energy through the heat sink placed on the Peltier surface. When there is an increase in trial time, there is also a voltage drop due to a significant decrease in $\Delta \mathrm{T}$ due to a shift in the heater directed at the thermoelectric device. The graph of the difference in temperature changes is shown in Figure 7, and the graph of voltage increase can be seen in Figure 8.

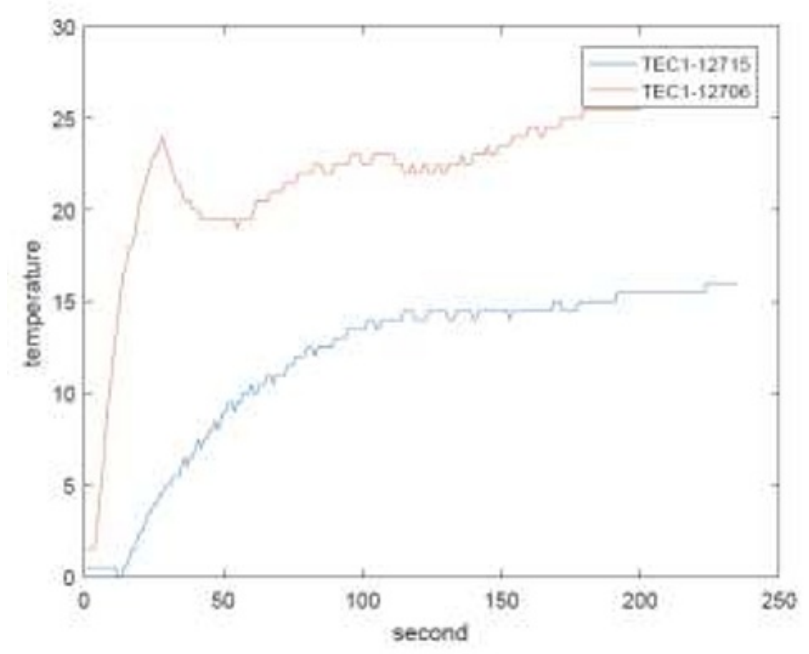

Fig. 7. Graph of difference in temperature change

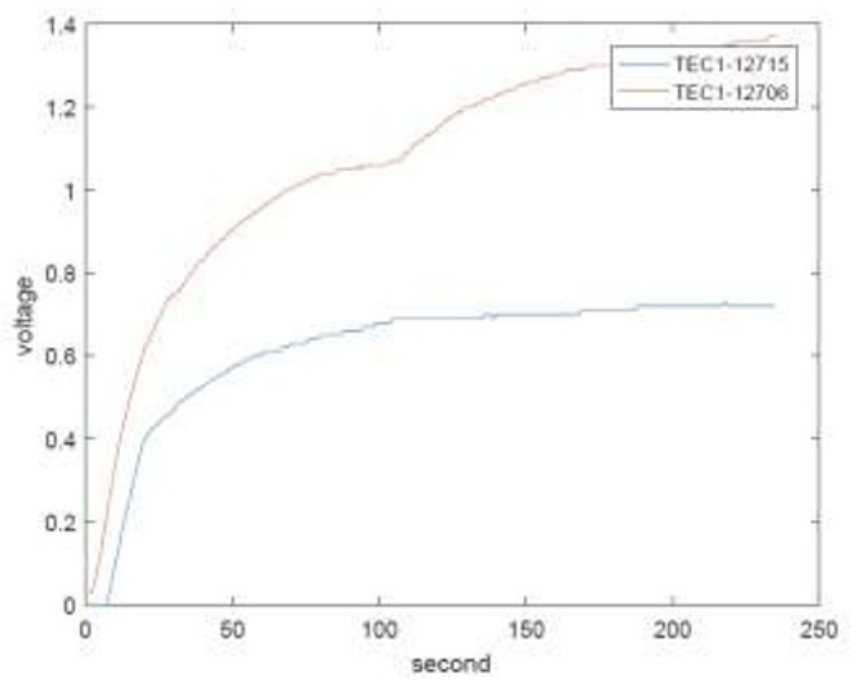

Fig. 8. Voltage increase chart 
After the experiment above, combining all of them in 1 graph so that the differences and the comparison of each test time are visible.

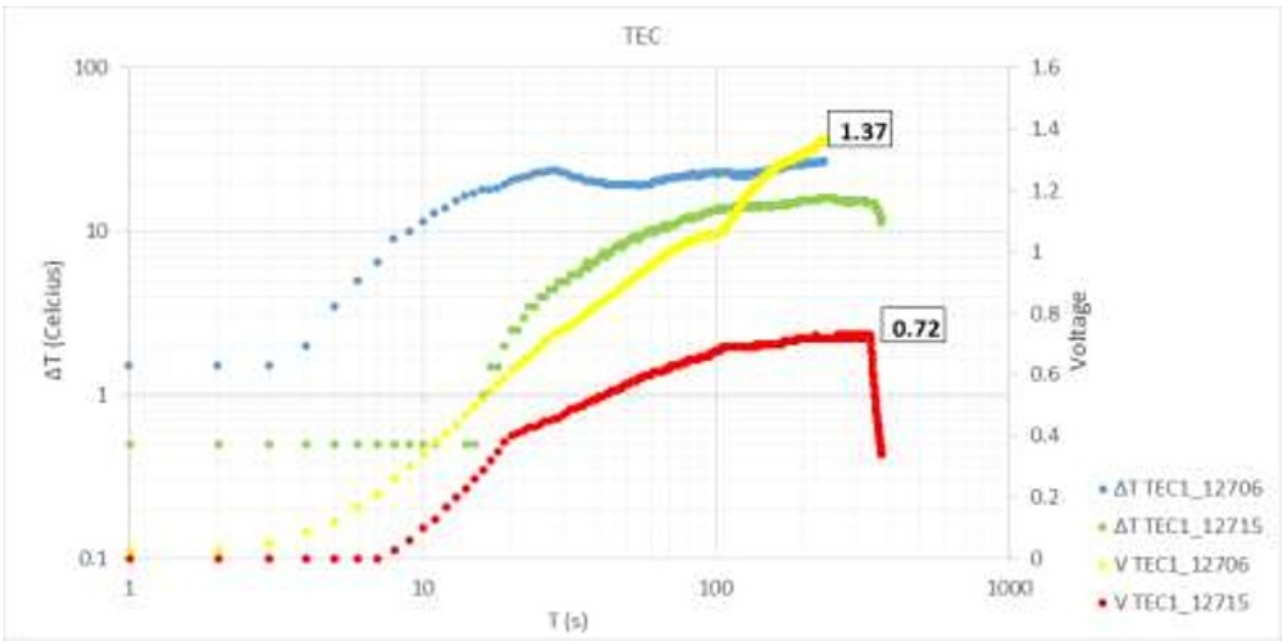

Fig. 9. The results of voltage measurements on thermoelectric TEC1-12706 and TEC1-12715 measurements in the laboratory

The results of voltage measurements on thermoelectric generators TEC1-12706 and TEC1-12715 in the laboratory with the same conditions as the simulation $\left(\mathrm{Th}=56{ }^{\circ} \mathrm{C}\right.$ and $\mathrm{Tc}=29^{\circ} \mathrm{C}$ ) as shown in Figure 9 shows the maximum voltage value of $1.37 \mathrm{~V}$ and $0.72 \mathrm{~V}$.

\section{Conclusion}

Measurements are made with conditions that the TEC does not receive current so that when the heat source is not centralized, there is a significant voltage drop from the thermoelectric. The conditions of laboratory experiments are carried out under open conditions, which can allow other heat transfer processes such as forced convection to occur. The results of conventional thermoelectric measurements in the laboratory serve as a reference related to how the electrical energy potential that can be generated from thermoelectrics in general. The thermal concentrator which can concentrate heat energy is then used to determine the effect and potential of the electric voltage that can be generated in a thermoelectric device if the application of a thermoelectric device is combined with a thermal concentrator.

\section{References}

1. E.M. Dede, P. Schmalenberg, C.M. Wang, F. Zhou, T. Nomura, AIP Adv., 6,5: 055113(2016). https://aip.scitation.org/doi/10.1063/1.4950861

2. P.R. Bandaru, K.P. Vemuri, F.M. Canbazoglu, R.S. Kapadia, AIP Adv., 5,5: 053403(2015). https://aip.scitation.org/doi/10.1063/1.4916220

3. M. Keidar, A. Shashurin, S. Delaire, X. Fang, I.I. Beilis, J. Phys. D. Appl. Phys., 48,48:1-4(2015). https://pdfs.semanticscholar.org/3029/9319e22210e552ac8a270e8caa4ca142615c.pdf 
4. C.T. Roman, R.A. Coutu Jr., L.A. Starman, Thermal management and metamaterials. In: MEMS and nanotechnology volume 2. T. Proulx (Eds). Springer, New York (2011). pp. 163-166. https://link.springer.com/chapter/10.1007/978-1-4419-8825-6_16

5. S. Mirapalli, P.S. Kishore, Int. J. Eng. Trends Technol., 19,5:279-284(2015). http://ijettjournal.org/archive/ijett-v19p249

6. F. Chen, D.Y. Lei, Sci. Rep., 5,11552(2015). https://www.nature.com/articles/srep11552

7. [7] T. Han, X. Bai, J.T.L. Thong, B. Li, C.W. Qiu, Adv. Mater., 26,11:17311734(2014). https://onlinelibrary.wiley.com/doi/abs/10.1002/adma.201304448

8. I. Peralta, V.D. Fachinotti, Sci. Rep., 7,1:1-8(2017). https://www.researchgate.net/publication/318659944_Optimizationbased_design_of_heat_flux_manipulation_devices_with_emphasis_on_fabricability

9. Z. Muslimin, R.N. Kaikatui, E. Palantei, I.S. Areni, S. Syarif, A. Suyuti, et al. IOP Conf. Ser. Mater. Sci. Eng., 619,1(2019).

https://iopscience.iop.org/article/10.1088/1757-899X/619/1/012022

10. W. Liu, C. Lan, M. Ji, J. Yao, J. Wang, B. Li, et al., Glob. Challenges, 1,6(2017). https://onlinelibrary.wiley.com/doi/pdf/10.1002/gch2.201700017 